\title{
Geography Education for Training Primary and Junior High School Teachers who have Geographical Skill
}

\section{Geography Education for Training Primary and Junior High School Teachers who have Geographical Skill}

KAWADA Tsutomu

Okayama University

Geographical skills have come to be thought of as a more important aspect of geography education at elementary and junior high school level due to the enforcement of a new curriculum from 2002. The ability of the teachers who teach geography will be tested on this basis.

A symposium concerning this was held by the Association of Japanese Geographers in the autumn of 2003.

In the discussion, it was indicated that under the new course of study it was important to recognize that the contents of study are improved and arranged so that duplication of the educational content between each school stage of primary, middle and high schools is eliminated. Furthermore in order to perform effective study in the following school stage, the necessity of clarifying what academic abilities should be learned by students in each school stage is being discussed. Moreover, the importance of systematic educational guidance using consistent targets in an ideal way was also emphasized as well as cooperation between schools for raising definite geographical skills in elementary secondary education.

In the Association of Japanese Geographers, a further symposium was held also in 2004. Here, the necessity of specifying concretely the contents of the geographical skills which should be taught at each school stage was re-emphasized. Moreover, there are reports which demand our attention that the number of children and students who fail to master the rudimentary knowledge and the concepts of geography education as well as falling into the stereotype of egocentrist behavior are increasing.

In addition, a report about the measures to promote geography education was also made in the Spring of 2003.

The number of citizens who completed their compulsory geography education is seen to in- crease rapidly when geography serves as an elective subject in the high school. In other words, it can be said that the role of the geography education in the compulsory education stage is increasing. However, some difficulties and issues with instruction in geography educational practice at elementary and junior high schools are also reported. Moreover, the grades of difficulty of geography educational practice at such elementary and junior high schools differ greatly depending on the degree of teachers' geographical knowledge, skills, and capability for self-reflection.

However, there are also many issues regarding the teacher-training of geographical skills at university level. Even some common consensus has not been achieved regarding what is indispensable geographical knowledge, skills, and consideration capability for a teacher who teaches geography. Moreover, it is hard to say that a proper program for making them learn is also prepared. As a result, the contents of lessons within a university are various, and may not necessarily have guaranteed the acquisition of the nature and skills required to become a teacher. Moreover, the state of cooperation among teachers in connection with geography education also influences the effectiveness of education at the university level.

Is This Subject a Part of the Curriculum?: Teaching of Human Geography at Teachertraining College

\section{ARAKI Hitoshi \\ Yamaguchi University}

We report on various issues in current training of teachers of geography, particularly human geography, at colleges of education. We investigated the number of lessons, and lesson contents of both teacher training courses and courses that are not teacher training courses, and the rational behind the lessons and training courses.

When asked the question, "What do you do to enhance geography education and what do you teach in geography?", the model reply was, “Ac- 
quire a geographical way of thinking, and then teach this to the children". But when this is followed up with the question, "But what do you mean by 'geographical way of thinking'?", there were almost no clear answers. In this regard, the students are all alike, as are the teachers. Considering that methods to learn, investigate and summarize are considered as important skills in geography, it is apparent that neither the point of having these skills nor how to use them are understood. In order to find out more, it is necessary to dig deeper, but we were afraid that it would only have lead to a poor discussion. By the way, most probably there is no consensus amongst social education teachers as to the meaning of the phrase "geographic". Considering this background, we think that not enough investigation has been done into why geography is part of primary education.

Within the limited time of a lesson, it is not easy to master how to effectively use the skills. However, basic questions such as why is geography taught at school, and why is it made part of primary education, which should be considered in order to realize effective training, seem to be lacking. Rather than focusing on geographic data, it is necessary to discuss the possibilities and limits of what can be taught based on the academic historical background rather than merely on discussion of the main points.

\section{Problems and Countermeasures for Education in Physical Geography at Fukuoka University of Education}

KUROKI Takahito

Fukuoka University of Education

In Fukuoka University of Education, there are six courses of lectures, Human Geography and Physical Geography, Theory of Geography, Foundation of Social Studies, Lectures in Physical Geography, Experiments on Physical Geography, and Seminar of Physical Geography are taught to students to train them in physical geography over four years. Nevertheless, it is difficult for students to master important elements of physical geography for many reasons. First, the number of courses is not always sufficient. Secondly, approximately 75 percents of the students did not take lessons of geogra- phy in their high school days. Thirdly, students misunderstand the basic elements of geography. Fourthly a lot of students have disliked geography since junior high school days. Fifthly students want to be a good teacher, so they never want to be a specialist in geography. Lastly there are no facilities for scientific analyses in Social Studies Education in this University. I think that four elements for understanding physical geography are ability of map reading, variable scale on time and space, relationship between human geography and physical geography, and its analytical methods. I endeavor to improve these courses in terms of enhancing their exact understanding of the elements and try to change their attitude to the discipline every year.

For example, 1) GIS training using free software in the Experiments on Physical Geography improved student's ability of map reading, 2) calculation of water volume on climatology or hydrology using various data book in the Theory of Geography helped in understanding variable scale on time and space, 3) field survey in various ground conditions in the Foundation of Social Studies and a few courses helped in understanding relationship between human geography and physical geography, and 4) experiments, observations and analyses using borrowed facilities from other teachers in the Seminar of Physical Geography helped in understanding analytical methods of physical geography.

In addition to understanding the elements, I think that students have to master 5 skills which they are learning, literature reading, field research, settlement and presentation of their teaching of physical geography with the aim of training them to be elementary school or junior high school teachers in this University. So, I attempt and lecture each course including a few trainings on selected skills suited to the student's grade of physical geography, and make them think about the relationships between contents of the lecture and National Courses of Study. 
Improvement of Geography Teacher Training on the Concept of "Comparative Study for Lesson Planning"

\author{
KUSAHARA Kazuhiro
}

Naruto University of Education

The purpose of this presentation is to suggest a curriculum design for improving a teachertraining course, in the case of the class "Practice Application of Integrated Studies in Education" tried from 2001 to 2003 in Naruto University of Education. Nowadays, teacher-training courses in the faculty of education are expected to reform a curriculum design toward strengthening relationship between disciplinary contents and educational strategies. We suggest that such a reformation is to be realized mostly by introducing the concepts of Comparative Study for Lesson planning (CSLP). The following aim, contents, and methods of the class are derived from our trial in the last three years.

1. An aim of the class is to foster professional knowledge and skills essential to geography teachers. A teacher-training course must guarantee enough opportunities to learn knowledge regarding a philosophical framework of geography education, and to master skills for practicing a meaningful geography class.

2. For achieving this aim, students are assigned to review any articles presenting the teaching- learning theories under dispute, and to build multiple hypotheses by applying them into geography education. Professors who major in pedagogy are responsible for guiding a typology on the identity of Social Studies, which accounts for reasons why these theories are proposed and opposed.

3. For clarifying effects of the hypotheses, a) teachers in attached school and b) students in training course are directed to develop different lesson plans on the same subject based on the two promising hypotheses. In the end, these plans are put into practice for verification. Professors who major in geography are responsible for supporting the experimental class from the point of discipline.

4. For example, the following opposing hypotheses have been examined in the class before; a) topography centered or issues centered, b) mastering skills or inquiring generalizations, and c) recognition of regions as reality or recognition of regions as social construction. These combinations just correspond to "theory adopted in national standards" or "antithesis to it".

It was found thorough questionnaires that most of the participants evaluated the CSLP design as valuable. They were especially satisfied with the experiences to compare multiple types of practices without sticking to one conventional theory. In concluding, the author should note that the CSLP is possible to promote a partnership between educators and geographers, staff in attached school and faculty in university, as well as provided the competency needed by teachers.

\section{Practical Difficulties of Geographical Skill in Elementary School}

$$
\begin{array}{r}
\text { KAW ANISHI Toshiyuki* and } \\
\text { MORISHIGE Kotaro** } \\
{ }^{*} \text { Otoshi Elementary School } \\
{ }^{* *} \text { Heta Elementary School }
\end{array}
$$

The practice of geographic skills, that is, methods of learning, investigating and summarizing, in an elementary school in Yamaguchi prefecture is reported. The following issues were taken up: 1. technical issues, 2 . the curricula and what is actually taught, 3 . the study contents and their significance.

As it is not easy for one home-room teacher to look after 30 students, helpers were sought, but without success. On top of the human-resource issue, the following, related to books and facilities were noted: Although it is supposed to be possible to make choices regarding the study of the manufacturing sector in Japan, in reality, there is a tendency to study the sector in units such as rice production, the fishing industry, and the car industry, that appear in the textbooks. However, school trips cannot be made to some industries because they are too far from the schools.

There is a question of what can be taught at each grade. To what extent must studying maps be taken in elementary school? Regarding the use of maps, the ability to think "Why is something on a map?" must be fostered in steps appropriate to the year of study. At what stage should something be appraised? When design- 
ing a course, thought should be given to how something taught in one grade ties in with what is taught in the next grade.

Classes that improve the ability to think and express your opinion are desired nowadays, but in practice, for teachers, there are difficult aspects to this; teachers are often confounded because it is not clear as to what should the students be made to think about or how they can be made to think. Similarly, it is also desired that the students acquire abilities to investigate and learn through experience, but finding out how to go about this is like feeling in the dark.

\section{What is Required for a Geography Teacher in a Junior High School?}

YUASA Seiji

Hiroshima University High School

In order for a teacher to teach geography in a junior high school, understanding the government guidelines for teaching correctly, having the capability to constitute a lesson, the capability to create a test, the capability to evaluate a student's activity, and the humanity which is pleased with watching the growth of a student are required.

In order to correspond to introduction of evaluation on an absolute scale, objective and common targets are also required. It becomes indispensable in that case to take into consideration the relationship between the government guidelines for teaching and the contents of a lesson.
It is important to build some tests for evaluating students. Under the present circumstances, the teacher must create those tests whilst reviewing each lesson. That is, if the contents of study are well constituted, the test can also be created well.

In the latest elementary and secondary education, there is a tendency to finish each study activity by checking a fixed correct answer. However, many-sided thinking of a student and the thought process are omitted, and the capability which supports growth is required of a teacher. Simultaneously, it is also important in a lesson for students to express their concern by themselves.

While evaluating process in that case, reports which the students created will be evaluated. The capability to evaluate such a report differs greatly by how far the teacher him/ herself has actually investigated. Moreover, this can be conceptualized as a capability which supports the continuous study of the students.

In order to support ways of turning students' concerns into geographical thinking, and suggesting the practical methods of using effective data, one ought to search for an attitude which watches a student's activity in the long term. A teacher can master the basic teaching capability centering on knowledge at schools. However, it is necessary to master skills relevant to the characteristic of a subject through university education. In conclusion, it should therefore be a more substantial part of the teacher's training system.

\section{Fundamental Study on the Maps of Asia-Pacific Areas Prepared by the Japanese Army}

\section{Introduction}

The former Japanese Army had made many maps of Asia-Pacific areas up to the end of the Second World War. These maps have been called generally gaihozus (maps of foreign areas), because they mostly illustrate the areas outside Japan proper. At present the maps of former Japanese colonies, such as Taiwan and Korea, made by non-military organization are also included in the category of gaihozu.

Just after the end of the Second World War, the Japanese Army incinerated gaihozus, because most of them had been classified as secret and seemed to become crucial evidence in the war criminal trials. However, some part of them, which survived this massive destruction, have been kept in libraries and geographical departments of universities in Japan and for- 